\section{Revista Brasileira de Literatura Comparada abralic}

ISSN 0103-6963

e-ISSN 2596-304X
EDITOR-CHEFE:

Rachel Esteves Lima

EDITOR EXECUTIVO:

Regina Zilberman

SUBMETIDO: 01.10 .2021

ACEITO: 05.11.2021

\section{COMO CITAR:}

TENNINA, Lucía.

Crítica Performática. Los desplazamientos y afecciones de la producción crítica y la producción literaria contemporánea. Revista Brasileira de Literatura Comparada, v. 24 , n. 45 , p. $40-54$, jan./ abr., 2022. doi: https:// doi.org/10.1590/2596$304 \times 202224451 \mathrm{t}$

\title{
Crítica Performática. Los desplazamientos Y AFECCIONES DE LA PRODUCCIÓN CRÍTICA Y LA PRODUCCIÓN LITERARIA CONTEMPORÁNEA
}

\author{
Performatic criticism. The dislocations and affections of critical \\ production and contemporary literature production. \\ Crítica performática. Os deslocamentos e as afecções da \\ produção crítica e a produção literária contemporânea.
}

\author{
LuCía Tennina ${ }^{1}$ \\ ${ }^{1}$ Universidad de Buenos Aires. Buenos Aires, Argentina. \\ E-mail: luciatennina@gmail.com
}

\section{RESUMEN}

En los últimos años, la idea de lo que es la literatura viene diluyendo sus fronteras en el discurso de la crítica al punto tal de que es posible encontrar objetos de análisis ligados a cruces con otros lenguajes. En este artículo se abordan una serie de producciones críticas, englobadas alrededor de la categoría "crítica performática", que se ven afectadas por dichas experiencias literarias y pretenden repensar, a partir de ellas, su soporte y su lugar de habla.

PALABRAS CLAVE: crítica literaria contemporánea; literaturas contemporáneas; campo expandido; performance; lugar de habla.

\begin{abstract}
In the last several years, the concept of literature has blurred its borders in the critical discourse, to the point that it is possible to find topics of critical analysis examined alongside other forms of discourse. This article will address examples of critical production identified within the category of "performatic criticism" that are affected by the writers' literary experiences and that, from these experiences, seek to rethink their support and their place of speech.
\end{abstract}

KEYWORDS: contemporary literary criticism; contemporary literature, "expanded field," performance; standing point ["lugar de fala"]

\section{RESUMO}

Nos últimos anos, a ideia do que é literatura tem diluído suas fronteiras no discurso da crítica a ponto de ser possível encontrar objetos de análise ligados a cruzamentos com outras linguagens. Neste artigo, são abordadas produções críticas, identificadas a partir da categoria "crítica performática”, que são afetadas por essas experiências literárias e buscam repensar, a partir delas, o seu suporte e o seu lugar de fala.

PALAVRAS-CHAVE: crítica literária contemporânea; literaturas contemporâneas; campo expandido; performance; lugar de fala. 


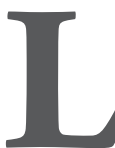

a problemática del campo expandido viene atravesando nuestras miradas sobre las producciones artísticas con gran intensidad en los últimos años. La idea de lo que es la literatura viene diluyendo sus fronteras en el discurso de la crítica al punto tal de que es posible encontrar objetos de análisis ligados al cruce entre música, artes digitales, artes visuales, etc. tomados como literatura. Ante esta revitalización de las formas literarias, la crítica en términos generales viene manteniendo un diálogo con ellas que no genera ningún tipo de dinamismo, sino que las aborda utilizando siempre las mismas recetas y trucos. Pero es posible, también, encontrar una serie de producciones que se ven afectadas por esas experiencias literarias y pretenden repensar su quehacer crítico a partir de ellas. En este artículo me propongo abordar prácticas críticas que cuestionan también sus propios manuales y se vuelcan a dialogar con estas discusiones respecto de los campos expandidos en su propia escritura $y$, en este sentido, también apuran un cuestionamiento a su lugar de habla.

\title{
CRÍTICA MANIFIESTO
}

“QQué es el crítico literario hoy en día?” se pregunta Flora Süssekind en una conferencia titulada "Límites inciertos", en abril de 2014 (SÜSSEKIND, 2014). En aquella conferencia la investigadora brasileña postula la necesidad de producir una "crítica manifiesto" que sea capaz de generar un "cortocircuito mínimo" en el juego de fuerzas que impone el corset del campo literario en función de pensar lo contemporáneo y de figurar nuevas formas de visualización y radicalidad. Para ello, plantea, es necesario asumir el desafío de considerar en el análisis un tipo de obra que no nos permita aplicar los "cajones" críticos con facilidad (esto es, género, clase, nación, etc.) que resultan, según Süssekind, en comprensiones restrictivas que parecen no ir más allá de oposiciones binarias sistémicas como la oposición entre ficción y testimonio, secuencialidad y fragmentación, constructivo y expresivo, etc. ¿Cuál sería el corpus sobre el cual debe trabajar la crítica hoy en día? Lo responde en un texto de 2013, publicado en el periódico $O$ Globo bajo los efectos de las jornadas de junio:

\begin{abstract}
Antes mesmo da eclosão das jornadas de junho, e das manifestações ainda em curso no país, um conjunto significativo de textos parece ter posto em primeiro plano uma série de experiências corais, marcadas por operações de escuta, e pela constituição de uma espécie de câmara de ecos na qual ressoa o rumor (à primeira vista inclassificável, simultâneo) de uma multiplicidade de vozes, elementos não verbais, e de uma sobreposição de registros e de modos expressivos diversos. Coralidades nas quais se observa, igualmente, um tensionamento propositado de gêneros, repertório e categorias basilares à inclusão textual em terreno reconhecidamente literário, fazendo dessas encruzilhadas meio desfocadas de falas e ruídos uma forma de interrogação simultânea tanto da hora histórica, quanto do campo mesmo da literatura. (SÜSSEKIND, párr.1).
\end{abstract}

El trabajo de la crítica, de acuerdo con Süssekind en un texto publicado en el mismo periódico en 2010, tiene que centrarse en encarar esos desafíos y esos impasses epistemológicos a los que este tipo de textos obliga, saliéndose del lugar "anacrônico" que responde a una "vontade" de retorno a algo cercano a las "Belas Letras" y un "apagamento de novos espaços de legibilidade" (SÜSSEKIND, 2010, párr. 6). Dichas conclusiones surgen de su desencanto al leer las necrológicas que escribieron muchos críticos como consecuencia de la muerte de Wilson Martins, evidenciando, según la autora, una reducción radical del disenso y, principalmente, una pérdida del lugar social de la crítica. "Talvez 
seja necessário, na discussão de um espaço ainda crítico para a crítica, matar mais uma vez Wilson Martins" (SÜSSEKIND, 2010, párr. 6), llega a decir la autora.

Süssekind propone un corpus para comenzar a pensar en ese tipo de experiencias en el que aparecen nombres de autores contemporáneos cuya producción cuestionaría el campo literario en la medida en que sus textos apuestan a la ampliación o destrucción de sus supuestos márgenes a partir de la resistencia que imponen a su definición, de ahí que la autora los denomine "objetos verbais não identificados" (SÜSSEKIND, 2013, párr. 3).

Un ejemplo tomado de la lista de autores mencionados es el texto “Delírio de Damasco" (2013), de Verónica Stigger, que originalmente fue una exposición montada en forma de placas sobre las vallas de la sede 24 de Maio del SESC São Paulo con textos tomados de frases oídas al pasar en la vía pública, rumores de la calle que se plasmaron como poesías. Se trata, según Süssekind, de un proceso de composición al estilo ready made que dialoga con la tradición oswaldiana apuntada ya en el epígrafe del libro. Otro ejemplo que conforma este coro de voces contemporáneas que nosotros como críticos deberíamos interpretar, según Süssekind, es la producción de la poeta Marília Garcia, en donde la voz y la escucha son una vez más los horizontes de escritura y donde se puede ver un juego de deslizamientos geográficos y focales (una ciudad en otra, voces múltiples en una voz). "Reajuste constante de entonação e de percepções que empresta configuração dinâmica a essas observações” dice Süssekind (2013, párr. 4). Inevitable no mencionar en la lista las experiencias textuales-plástico-sonoras de Nuno Ramos, la poesía de Carlito Azevedo, la narrativa gráfica de Lourenço Mutarelli. Todos textos en los que es posible encontrar "un tensionamento de gêneros, repertório e categorias basilares à inclusão textual em terreno reconhecidamente literário, fazendo dessas encruzilhadas meio desfocadas de falas e ruídos uma forma de interrogação simultânea tanto da hora histórica, quanto do campo mesmo da literatura” (SÜSSEKIND, 2013, párr. 3).

Lo que parece interesarle a Süssekind son los ecos de otros lenguajes que no son solamente el texto escrito en las producciones literarias contemporáneas. En otras palabras, la autora apunta a salirse de la idea de campo literario como territorio de trabajo del crítico.

De acuerdo con la teoría de Bourdieu (1995), el campo se define por un capital, por reglas y por agentes posicionados en ese campo luchando por ese capital (posicionados de manera desigual). Cada campo es diferente (porque depende de la función del capital) pero su funcionamiento es el mismo. Los campos son autónomos entre sí y su límite está al interior del juego de cada uno y en su relación con otros campos. La propuesta de Süssekind tiene que ver con pensar más allá las reglas y capitales simbólicos de cada campo y centrarse en la relación, justamente, más allá de las fronteras entre los quehaceres artísticos.

En el artículo, Süssekind, muy en la línea de un manifiesto, se enfrenta a dos posicionamientos respecto de la literatura. Uno tiene que ver con la "professionalização do escritor” (2013, párr. 5) ligada a la construcción de un mito alrededor suyo o, para entenderlo en otros términos, con lo que Diana Klinger entiende como "efeito do real além da ficção", esto es aquellos aspectos autoficcionales que "quebram com a ficcionalidade e apontam para além da ficção" (KLINGER, 2007, p. 45). Ese "más allá de la ficción” se vincula con una de las características de la literatura contemporánea que posiciona al libro como parte de un proyecto/proceso que atraviesa otros lenguajes y soportes donde se pone en juego, 
también, al propio autor como figura pública. Süssekind propone que la crítica se aleje del análisis de dichos autores, que responden según ella solamente a una lógica del mercado más que a una lógica de la "hora histórica”. Y asimismo plantea un segundo rechazo de "a ressurreição velada da literatura como representação especular” (2013, párr. 5), que tiene que ver con asociar a la literatura con cuestiones identitarias sin ambigüedades y sin complejidades. Esta crítica literaria se distancia fuertemente de los análisis que abordan producciones marginalizadas bajo la idea de que esas producciones se acomodan en los géneros ya establecidos y anacrónicos, como el naturalismo o el testimonio.

Me interesa subrayar el comienzo del artículo de Süssekind, "antes mesmo da eclosão das jornadas de junho", donde parece hacer un paralelismo entre el corpus que debe trabajar el crítico y los hechos de las calles, que se resisten (aún más en esa época) a ser definidos. El año 2013 estuvo atravesado en Brasil por pequeñas manifestaciones como oposición al aumento de las tarifas del transporte público lideradas por el "Movimento Passe Livre" (MPL) y el día 6 de junio la protesta en São Paulo reunió cinco mil estudiantes, suma que hasta ese momento se consideraba muy numerosa. Las protestas en las calles fueron creciendo y las pancartas fueron diversificando sus demandas al punto tal de que se llamaron a esas manifestaciones las “jornadas de junio”. Millares las personas salieron a la calle, de todos los posicionamientos políticos; se trató de un abre aguas en la historia brasileña, que dio lugar a una "explosión feminista" (HOLLANDA, 2018) y le dio fuerza al movimiento negro (BOGADO, 2018 , p. 23) pero también fue la oportunidad para que los medios de comunicación insistieran con el mensaje sobre el descrédito en la política ligado a la corrupción del Estado y la derecha le hiciera eco creyendo que llegaba el final del lulismo (MIGUEL, 2019, p. 156). Fotos, relatos y videos en tiempo real se empezaron a compartir en la redes, hashtags como \#VemPraRua o \#VemPraJanela fueron posteados por miles y miles de usuarios. Y el número de personas fue creciendo; el 17 de junio se llegaron a contabilizar 270 mil personas en 30 ciudades de Brasil y alrededor de un millón y medio de personas en 130 ciudades de Brasil el 20 de junio. Una de las frases del momento eran "disculpem o trastorno, estamos mudando o país". Había un clima de optimismo latente bajo el horizonte de una nueva generación política pero lo cierto es que también había un clima de indefinición de hacia dónde llegaría ese cambio.

La hipótesis de Süssekind sostiene que ese nuevo momento en la realidad brasileña estaba ya delineado en la literatura y sería tarea de la crítica que trabaja con una sensibilidad más contemporánea leer o relacionarlos con sus lecturas, o quizás adelantarse a los sucesos que atraviesan las sociedades contemporáneas. El crítico podría, así, dialogar con todas las narrativas del presente. La crítica literaria de un Brasil al borde del abismo no se posiciona, entonces, desde un lugar de verdad, sino desde lo incierto, lo tentativo, lo inexacto. Pareciera que la escritura y la metodología de la crítica se ven atravesadas inevitablemente por la exterioridad todavía no cristalizada en definiciones ni conceptos.

\section{CRÍTICAFICCIÓN}

El posicionamiento de Süssekind está directamente ligado a la actitud crítica que empieza a tomar Josefina Ludmer en 2008 con su renombrado artículo virtual "Literaturas 2.0" y que termina de definir en su libro Aquí América Latina. Una especulación (2010). En ese texto y en dicho libro la autora sostiene una hipótesis más o menos parecida a la de Süssekind, según la cual la literatura contemporánea 
pone en cuestión los límites o fronteras del campo a partir de una serie de prácticas de escritura que experimentan con otros lenguajes y que ponen en jaque la idea de autonomía, básicamente:

\begin{abstract}
Muchas escrituras del presente atraviesan la frontera de la literatura [los parámetros que definen qué es literatura] y quedan afuera y adentro, como en una posición diaspórica: afuera pero atrapadas en su interior. Como si estuvieran 'en éxodo'. Siguen apareciendo como literatura y tienen el formato libro (se venden en librerías y por internet y en ferias internacionales del libro) y conservan el nombre del autor (se los ve en televisión y en periódicos y revistas de actualidad y reciben premios en fiestas literarias), se incluyen en algún género literario como 'novela', y se reconocen y definen a sí mismas como literatura. Aparecen como literatura pero no se las puede leer con criterios o categorías literarias, como autor, obra, estilo, escritura, texto y sentido. No se las puede leer como literatura porque aplican a 'la literatura' una drástica operación de vaciamiento: el sentido (o el autor, o la escritura) queda sin densidad sin paradoja, sin indecibilidad, "sin metáfora", y es ocupado totalmente por la ambivalencia: son y no son literatura al mismo tiempo, son ficción y realidad. (LUDMER, 2010, p. 151).
\end{abstract}

El lenguaje literario para Ludmer está dado actualmente por el mercado y el formato libro, pero los materiales literarios no pueden leerse literariamente, dado que forman parte de la "fábrica del presente" que es la imaginación pública, esto es "todo lo que se produce y circula y nos penetra y es social y privado y público y "real". Ella habla en cierto momento de "prácticas literarias territoriales de lo cotidiano", de hecho, fundiendo en esa categoría la idea de ficción y realidad: "Fabrican presente con la realidad cotidiana y esa es una de sus políticas" (LUDMER, 2010, p. 151). La marca del régimen de las escrituras del presente es, así, la "ambivalencia", no solo en las mismas literaturas postautónomas, sino en el registro de que junto a dicha tendencia siguen apareciendo escrituras que se resisten a esta condición acentuando las marcas de pertenencia a la literatura autónoma, de la misma manera que lo sostiene Süssekind.

El libro en el que se enmarca este artículo se llama Aquí América Latina. Una especulación y comienza con una advertencia metodológica: "para poder entender el nuevo mundo (y escribirlo como testimonio, documental, memoria y ficción) necesitamos un aparato diferente del que usábamos antes" (LUDMER, 2010, p. 9). La metodología que ella inventa en este libro es la del subtítulo, la "especulación", que tiene que ver con pensar y teorizar muchas veces sin base teórica y con maquinar y calcular ganancias, también. "En este libro, especular sería pensar con imágenes y perseguir un fin secreto” (LUDMER, 2010, p. 10). La cuestión del secreto en este texto no es menor, porque el libro está montado como un diario íntimo: ella escribe un diario íntimo de una profesora argentina que trabaja en EEUU y que llega a Buenos Aires en el año 2000 durante su año sabático. Como define Arfuch a estos géneros en su libro El espacio biográfico:

El diario cobija sin duda un excedente, aquello que no termina de ser dicho en ningún otro lugar, o que, apenas dicho, solicita una forma de salvación. De alguna manera, contiene el sobrepeso de la cualidad reflexiva del vivir. Pero también realiza, vicariamente, aquello que no ha tenido ni tendrá lugar, ocupa un espacio intersticial, señala la falta. Más que un género, es una situación (un encierro) de escritura. (ARFUCH, 2010, p. 112).

$\mathrm{Al}$ ser un diario, está narrado en primera persona y se centra en un presente del "aquí y ahora" tomando como base lo que ella llama "imaginación pública", esto es "todo lo que circula, el aire que 
se respira, la telaraña, el destino" (p. 11). Habla así de lo que dicen los diarios, de las novelas de la

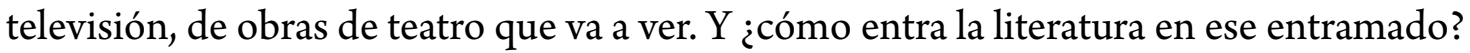

\begin{abstract}
Usar la literatura como lente, máquina, pantalla, mazo de tarot, vehículo y estaciones para poder ver algo de la fábrica de la realidad, implica leer sin autores ni obras: la especulación es expropiadora. No lee literariamente (con categorías literarias como obra, autor, texto, estilo, escritura y sentido) sino a través de la literatura, en realidadficción y ambivalencia. Usar la literatura para entrar en la fábrica de realidad. (LUDMER, 2010, p. 12).
\end{abstract}

La literatura entra como un dato más que se le cruza a Ludmer y lo introduce a partir de diálogos con escritores o críticos. "Caminata con Tamara Kamenszain en el Jardín Botánico. Tema: cierta poesía actual” (LUDMER, 2010, p. 105). “¿Qué contás? me dice Tamara cuando nos encontramos aquí para caminar y charlar sin parar...para caminarhablarcontar ¡Felicidad! ¿Cómo va tu diario del 2000?” (LUDMER, 2010, p. 105). Diálogos que, por otro lado, la corren a Ludmer del lugar auto-confirmante de la posición de autoridad en la temática: "Tamara cuenta: Más de una vez me dijiste que la poesía es algo que te deja medio perpleja, que no sabés qué decir cuando leés un poema” (LUDMER, 2010, p. 106). La literatura va entrando como parte del proceso de pensamiento de Ludmer que es un poco ese "caminarhablarcontar". Va mostrando la trastienda en primera persona del pensamiento, el proceso, por ejemplo, del descubrir a la literatura más allá de la idea de campo. La escritura es central en este proceso crítico, situarse en el aquí y ahora del crítico, en general desde una primera persona, transformando el texto en una performance en tanto acto de exploración de la subjetividad.

En el texto de Ludmer esa concepción respecto de las escrituras del presente afecta a la propia dicción crítica de Josefina Ludmer, de una manera incluso más profunda que la que se asomaba en el comienzo del artículo de Süssekind sobre los sucesos de junio de 2013. El libro de Josefina Ludmer es un experimento coral que muestra la transformación del funcionamiento de la literatura y de la crítica literaria a partir de, dice Ludmer: "una realidad que no quiere ser representada porque ya es pura representación" (2010, p. 151). Aquí América Latina es, en sí mismo, una "críticaficción" que no sigue las estructuras de un libro académico y, en este sentido, abre también un debate en torno de los modos enunciativos de puesta en forma del conocimiento de la crítica.

Este momento en el que Ludmer escribe este texto está también enmarcado por sucesos históricos radicales en las calles por donde la autora transita, es imposible olvidar que meses después de la escritura de este libro explota la llamada "crisis del 2001", que es un abreaguas en la historia argentina luego de que el levantamiento popular producto de una pobreza extrema provocada por las políticas neoliberales de esos años llevará a la renuncia del presidente bajo el lema del "que se vayan todos". La crítica de una Argentina al borde del abismo no se posiciona, tampoco, desde un lugar de verdad, sino desde lo incierto, lo tentativo, lo inexacto, tal y como sucede en el artículo de Süssekind. Pareciera que la escritura y la metodología de la crítica se ve atravesada inevitablemente por una "estructura de sentimientos" diría Raymond Williams, imposible de cristalizar en lecturas cerradas.

El posicionamiento abstencionista característico de la crítica literaria se pone en cuestión en estos textos que parten de una auto-reflexión sobre su auto-discurso y su subjetividad profesional a partir de un cuestionamiento de base en relación con la propia idea de literatura. Se trata de un desplazamiento de las reflexiones respecto del objeto de estudio a la propia producción crítica que se despliega en una performance sin límites disciplinares definidos. 
Y el espacio de actuación de ese proceso es la escritura. Las experiencias de Süssekind y de Ludmer apuntan a la asunción de la escritura como espacio de experimentación; no hay tanto una necesidad de interpretar, sino de de ir en contra de la interpretación, utilizando palabras de Susan Sontag, que tiene que ver con "La mejor crítica, y no es frecuente, procede a disolver las consideraciones sobre el contenido en consideraciones sobre la forma” (1984, p. 25).

\title{
CRÍTICA EN OBRAS
}

La crítica asume, entonces, un rol en el plano de la escritura, y en este sentido resulta ineludible la figura de Barthes al asociar la idea de crítica con la de escritor:

¿Acaso puede haber leyes de creación válidas para el escritor, pero no para el crítico? Toda crítica debe incluir en su discurso (aunque sea del modo más velado y más púdico) un discurso implícito sobre sí misma; toda crítica es crítica de la obra y crítica de sí misma" (BARTHES, 2003, p. 348).

La preparación de la novela. Notas de cursos en el College de France 1978-1979 (2005) es un claro ejemplo de este tipo de ejercicio crítico autorreferencial, dado que ahí Barthes aborda el gesto crítico desde el lugar de la práctica: se trata de un conjunto de clases que parten de la postulación de una novela por hacer, parte de la propuesta de hablar sobre la novela desde la posición del que la hace. Como lo adelantó en "Mucho tiempo he estado acostándome temprano", conferencia que dio en el Collège de France en 1978, la propuesta sería la siguiente:

\begin{abstract}
Me pongo, efectivamente, en la posición del que hace una cosa, y no del que habla sobre una cosa: no estudio un producto, endoso una producción; anulo el discurso sobre el discurso; el mundo ya no se me acerca bajo la forma de un objeto, sino bajo la de una escritura, es decir, una práctica: paso a otro tipo de saber (el del Aficionado) y en eso es en lo que estoy siendo metódico. "Como si”: ¿ no es acaso esta fórmula la propia expresión de un discurrir científico, como se ve en matemáticas? Hago una hipótesis y exploro, descubro la riqueza de lo que de ella se deriva; postulo una novela por hacer, y así, de esa manera, puedo esperar aprender más sobre la novela que considerándola solamente como un objeto ya hecho por los otros. (BARTHES, 2009, p. 406).
\end{abstract}

El planteo barthesiano apunta a una especie de performance del quehacer crítico, ir lidiando con una propuesta lanzada al público (en el caso de él, los estudiantes) para ir pensando sobre el tema y sobre el sujeto.

Es interesante pensar la experiencia de Süssekind y Ludmer a la luz de la propuesta de Barthes porque sus trabajos responden a la idea de que la voz del crítico forme parte del proceso de investigación. Este impulso por salirse del lugar de observador de un objeto a ser estudiado y activar una metodología que considere el conocimiento como proceso y el investigador como un elemento que afecta la investigación.

Inspirada directamente en las clases de Barthes, la crítica y escritora brasileño-argentina Paloma Vidal monta en 2016 el proyecto Em Obras, proyecto transdisciplinar de conferencias performáticas, que se llevó a cabo por primera vez durante la V Jornada da Pós-Graduação em Língua Espanhola e Literaturas Espanhola e Hispano-Americana da Universidade de São Paulo, proyecto que fue presentando luego en otros espacios también, como centros culturales y salas de teatro: 
Elas são basicamente apresentações, no formato de palestra, que duram em torno de 40 minutos. $\mathrm{O}$ formato é basicamente esse, muito simples, com uma mesa, um computador, um datashow. Por meio desse formato, o projeto traz uma série de questões teóricas e críticas interessantes. Talvez a ideia principal do projeto seja a do processo, a de que o que se exibe, o que se apresenta, é a obra que está sendo trabalhada, que está "em obras", em construção. O que a gente apresenta é a preparação da obra, ou seja, os diversos materiais, as ideias, os temas, os fantasmas. (VIDAL, 2016, párr. 2).

El trabajo de Paloma Vidal no solamente es el de curadora, sino que también realiza una conferencia que se titula, en diálogo explícito con Barthes, "no escribir"; es decir, la preparación de la obra sin que la obra llegue nunca. Paloma Vidal es una crítica literaria también "indefinida", tal y como señala a sí mismo Barthes en su "Lección Inaugural” (BARTHES, 1998, p. 113). De hecho, hoy en día, cuando la llaman para hacer una conferencia, ella hace performances, ya no da más charlas tradicionales.

Em obras es un proyecto colectivo, participan en él otras mujeres ligadas a las artes y a la literatura de diferentes formas cumpliendo diferentes funciones. Algunas de ellas son Cynthia Edul, dramaturga, Diana Klinger, crítica literaria, Elisa Pessoa, artista visual, Ilana Feldman, crítica de cine, Marília Garcia, poeta, Veronica Stigger, escritora. Vale destacar que este grupo, si bien no se afirma como un colectivo, trabaja colectivamente, aunque los productos son individuales. De lo que se trata en las performances es de que los lenguajes entren en un diálogo sin que alguno preceda al otro sino que convivan en un mismo ensayo, experimento, prueba o, como diría Marília Garcia en su propia performance que se volvió libro parque de las ruinas, en un mismo test:

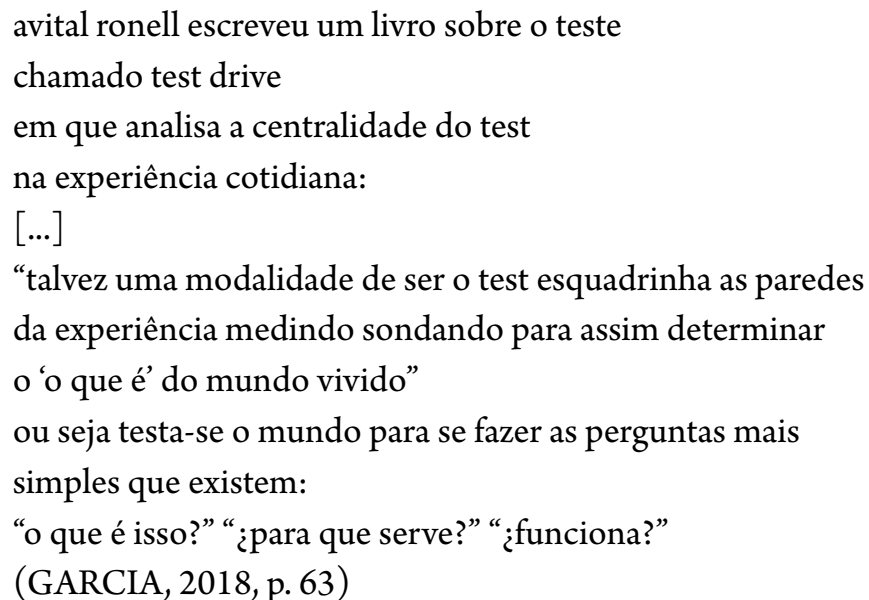

Son performances que parten, tal y como la cita de Marília lo dice, de las preguntas más básicas de cada disciplina. Y, en todos los casos, la búsqueda apunta, también, al cuestionamiento de la idea de autoridad que está detrás de la idea de autoría. La autoría aquí no se posiciona como garantía de la verdad, sino como una provocación, como un juego que interactúa con la noción de sujeto.

En general todas las presentaciones se cruzan con una intención más biográfica, pero también se relacionan con un interés teórico y académico. Parten de trabajos en proceso y la idea es mostrar esos procesos en las conferencias, mostrar los bastidores que forman parte de la escritura y que en general se dejan afuera. 


\section{POTENCIA CRÍTICA}

La performance crítica del proyecto curado por Vidal, en definitiva, trata de que los procedimientos experimentales que ya se dan en la literatura y la poesía, se den también en la crítica. Diana Klinger, una de las participantes del proyecto Em obras piensa su propia producción a partir de este impulso:

Mi primer libro es sobre escrituras del yo, es un libro extremadamente careta porque en ningún momento digo "yo" en ese libro. Una vez una persona me cuestionó eso. Y yo tuve que escribir mi segundo libro para responder a esa pregunta. Para mí fue una transformación darme cuenta de que la crítica podía asumir ciertos riesgos que la literatura ya estaba asumiendo. Yo pensé que ese segundo libro donde digo "yo" iba a ser un fracaso académicamente. Y nada que ver. Y eso fue como una especie de confirmación. Es como la historia de Kafka en "Ante la ley", donde el tipo está ahí tratando de entrar toda su vida y le dicen que no y no entra y al final de su vida le dicen,'la puerta está abierta, si vos no entraste ...' Y para mí es un poco eso, yo pensaba que no podía escribir así, y después que escribís así decís por qué, quién me va a decir que no. Es un poco esa la idea, no hay protocolos para la crítica. (KLINGER, 2020, s/n).

Las referencias de Diana Klinger en esta cita remiten a su primer libro Escritas de si, escritas do outro. O retorno do autor e a virada etnográfica, publicado en el año 2007, texto basado en su investigación de doctorado centrada en la problemática del "retorno del autor" y el "giro etnográfico" en la literatura contemporánea latinoamericana y a su siguiente libro, Literatura y ética. De la forma a la fuerza, del 2014, donde el foco de la atención está en el terreno de la literatura y la vida.

Este último libro consiste en otro ejercicio crítico performático destacable por su interacción con la producción contemporánea. Se trata de un libro que está estructurado a partir de tres cartas personales, es decir que se estructura a partir de la primera persona y de una concepción transversal respecto de la literatura, la crítica y la vida, guiada a partir de la noción de ética de Spinoza y el sentido de la potencia-encuentro: "spinozianamente, a obra deixaria de ser pensada como objeto para ser percibida como ato: ela só vai ter um sentido (para mim) quando producir reverberações (em mim), e desse encontro entre mim e a obra resulta um aumento de (minha) 'potência de existir'" (KLINGER, 2014, p. 56). Ese es el terreno de la ética planteado por Spinoza que aparece en el título del propio libro de Klinger y que tiene que ver no con el bien y el mal, sino con los encuentros que potencian lo bueno y los que potencian lo malo, es decir, con un campo de fuerzas que potencia composiciones y descomposiciones. En definitiva, la propuesta apunta a pensar al sujeto, a la literatura, a la lectura y a la escritura a partir, no desde sus identificaciones (definiciones) sino desde su poder de afectación. Es siempre un sujeto en relación, no un sujeto pleno, íntegro, haciendo eco explícito de las nociones de Deleuze y Guattari. Y es desde ahí, desde donde construye este libro, desde las potencias de las relaciones. En primer lugar, la potencia de las amistades:

Si te escrevo essa carta, Lu, é porque a minha "pesquisa" (não gosto dessa palavra) se tornou inseparável da amizade, dos diálogos cotidianos (e não só dos diálogos acadêmicos que fazem parte de qualquer pesquisa), das conversas que tive e tenho com você e, também à distância, com tantos outros amigos. Este livro é para e de meus amigos. As ideias que se tecem no diálogo não pertencem nem a um nem o outro, mas exclusivamente à relação. (KLINGER, 2014, p. 13). 
El libro abre con un escrito íntimo dirigido a una amiga donde se da a entender que la cotidianeidad compartida con ella y otros amigxs es estructural al pensar su vida académica e intelectual.

Junto con este tipo de afecto, está la potencia del deseo. De hecho, la primera carta habla de un hombre desconocido que tiene al lado en la biblioteca mientras escribe y de su atracción por él. Y luego afirma: "é preciso não esquecer, no entanto, que o desejo é para Deleuze, simultaneamente, um "afeto" produtivo: o desejo é uma máquina capaz de diversos agenciamentos e, portanto, também fluxo, devir, linha de fuga, rizoma. Aí residem as potencialidades da arte e da literatura" (KLINGER, 2014, p. 157). El deseo, de todos modos, no pasa solamente por la atracción hacia un cuerpo masculino, sino que va tomando otras formas a lo largo del libro. Los deseos abren la posibilidad de pensar nuevas formas de agenciamiento a través de la transformación creativa que implican los diálogos, las miradas, los encuentros y los ambientes, creando narrativas que no responden a los esquemas preconcebidos.

El libro también se construye desde la potencia de la lectura que, en la medida en que se van nombrando, va constituyendo el corpus de análisis:

Julio Cortázar, Tamara Kamenszain, Roberto Bolaño. Aparentemente, nada em comum entre eles: nem
as formas, nem os estilos, nem os gêneros, nem os temas. O que os reúne no espaço desta constelação é
apenas uma forma de lê-los a partir do que neles se manifesta como uma potência crítica. Tento pensar
essa potência a partir da autofiguração. São breves textos independentes entre si. Neles quero sugerir
algumas possibilidades de como a literatura nos afeta, como me afeta, a partir de minha própria história,
mas acreditando que esses "afetos" possam trascender minha percepção individual. (KLINGER, 2014,
p. 83-84).

La propuesta que plantea Klinger aquí, la forma de hacer crítica que ella entiende como salida a lo que ella llama "protocolos" de la disciplina (KLINGER, 2014, p. 118), se puede resumir bajo la idea de "potencia crítica". Bajo este programa se puede comprender que el subtítulo del libro sea "de la fuerza a la forma”: es en el campo de fuerzas que se consigue una forma. Pero el subtítulo dialoga no solo con toda la literatura de los afectos, sino que también nos plantea una especie de programa ligado a una escritura crítica que gane fuerza en la forma.

De la misma manera que con Ludmer, el libro de Klinger tiene también un cuaderno de notas como un puntapié para la escritura del libro, pero un cuaderno de notas que ya no está, que está perdido. El perder todo y empezar de cero es una constante en este libro: perder y encontrar la literatura de Cortázar, perder y encontrarse con su judaísmo, perder y encontrar al padre, perder y encontrarse con su historia personal. Todo a partir de la lógica barthesiana del punctum, ese sentido obtuso y discontinuo que interrumpe el curso de la historia. Esa resistencia del sentido, de algo que queda fuera de la estructura.

Y el libro, antes de pasar a la bibliografía, cierra con agradecimientos y una oración final donde le agradece a su hijo, "a meu filho, Nano, que com o seu sorriso lindo e seu olhar esperto me dá, a cada dia, forças para continuar” (KLINGER, 2014, p. 194). Su hijo que le da fuerzas para seguir también sería su ética. Las fuerzas para seguir viviendo y para seguir escribiendo en este caso irían de la mano. 


\title{
CRÍTICA PERFORMÁTICA
}

Propongo el concepto de "crítica performática" para comprender en conjunto estos desplazamientos críticos que vengo analizando hasta aquí en la medida en que en todos ellos se produce una puesta en escena del proceso crítico. Como señala Klinger en el capítulo "Autoficción y performance" de su libro Escritas de si, escritas do outro, O retorno do autor e a virada etnográfica: "A arte da performance supõe uma exposição radical de si mesmo, do sujeito enunciador assim como do local da enunciação, a exibição dos rituais íntimos, a encenação de situações autobiográficas” (KLINGER, 2007, p. 56). Cada una de estas producciones ponen en evidencia las fragilidades de la voz crítica objetiva, posicionada desde el lugar del saber, dejando lugar al despliegue de las intimidades del proceso crítico.

Además, la performance consiste en una comunicación artística con el entorno, como apunta Diana Taylor: "Las performances operan como actos vitales de transferencia, transmitiendo el saber social, la memoria y el sentido de identidad” (2012, p. 22). La performance estaría así ligada a la acción y la transformación, es un medio de intervención en el mundo, digamos, una forma de nombrar simultáneamente procesos que exceden las posibilidades de actuar más disciplinadas.

Hablo de performance, además, en la medida en que estas producciones críticas activan tensiones respecto de los discursos instituidos y proponen desplazamientos respecto de la imaginación de lo real a partir de una atención en la construcción (TAYLOR, 2012, p. 33).

Pensando en términos performáticos los textos de Süssekind, de Ludmer, de Vidal y de Klinger, es posible señalar diversas consecuencias de auto-transformación del lugar de habla de la crítica.

Por un lado, en el caso de Ludmery de Klinger, la acción performática desde el espacio autobiográfico las lleva a la puesta en escena ficcional de diálogos con otros, es decir el montaje de una performance afectiva en el sentido de lazos de amistad y en el sentido de affectus, es decir, el ser afectado, o, como explica Deleuze, "la transición vivida del estado precedente al estado actual" (DELEUZE, 2003, p. 81).

Por otro lado, la performance crítica de Süssekind explora el terreno de la "iracundia”, otro tipo de afecto, como señalan Aguilar y Cámara en su libro La máquina performática (2019):

\begin{abstract}
la iracundia es un afecto que cumple variados propósitos: poner en crisis el lazo social, producir antagonismos allí donde se pensaba que había comunidad, romper con pactos explícitos o implícitos [...]. En este sentido, la iracundia es una performance que funda un espacio donde cuerpos y voces se presentan como verdaderos e inesperados. (p. 115).
\end{abstract}

Tomando en cuenta este tono desde el cual monta su hipótesis, se puede entender por qué Süssekind denomina "crítica manifiesto" a la crítica que ella pretende como "necesaria", una crítica que se construye desde el antagonismo y desde un tono programático que pretende cortar con un cierto estado de la cuestión y fundar nuevos modos de hacer.

La puesta en escena del proceso crítico de Paloma Vidal, por su parte, estructura su lugar de habla desde la intensidad de lo efímero que forma parte del proceso crítico previo a la escritura. A partir de la exhibición en vivo de esos trabajos, sobre los cuales casi no hay registros, la voz crítica se posiciona sobre la parte más frágil de la materialidad de su trabajo. Como afirman Bormann y Brandstetter (apud Ayerbe, 2017, p. 560), "El discurso de la performance da testimonio de un vacío, de una pérdida. Solo 
se convierte en un objeto accesible, en un objeto al que nos podemos referir, sobre el que podemos discutir o podemos juzgar, si pagamos el precio de su desaparición [...]” (p. 46). El proyecto Em obras se monta justamente sobre esa idea de no presencia plena del producto crítico que el propio título transmite.

\section{CRÍTICA DESCOLONIZADA}

Los textos que fui mencionando hasta aquí y que opté por entender como performáticos tienen la particularidad de estar narrados en primera persona, "traicionando la regla objetivadora del saber académico cuya pretensión de validez y sistematicidad se apoya generalmente en la indefinición de la persona”, diría Nelly Richard (2009, p. 73). Se trata de experimentos críticos sin dudas fuera de manual que, sin embargo, encuentran su lugar de publicación en espacios hegemónicos, es decir, en editoriales muy consagradas (como Ludmer por Eterna Cadencia, Klinger por la editorial 7Letras y Rocco), en instituciones oficiales (como las universidades o centros de exposiciones donde se exhibió Em obras) o en uno de los periódicos más centrales de la prensa brasileña (como el periódico O Globo donde publicó Süssekind).

Es fundamental tener en cuenta la posición de privilegio de las voces de las críticas que se permiten hacer públicos estos ejercicios a partir de sus trayectorias, aunque resulta inevitable pensar también ese privilegio desde el punto de vista de la raza: en todos los casos estamos hablando de profesoras universitarias blancas cuyas producciones resultan indiscutibles en términos de valor científico. Es muy diferente cuando ese tipo de ejercicios lo realiza una crítica no blanca, dado que se percibe una diferencia radical en el impacto de esos textos, como muchos testimonios lo evidencian. Dentro de la teoría feminista negra se pueden leer muchas discusiones que se ligan con esta problemática. Grada Kilomba, por ejemplo, en su libro Memórias da plantação dice:

\footnotetext{
Interessante, mas acientífico; interessante, mas subjetivo; interessante, mas pessoal, emocional, parcial: "Você interpreta demais", disse uma colega. "Você deve achar que é a rainha da interpretação". Tais comentários revelam o controle interminável sobre a voz do sujeito negro e o anseio de governar e comandar como nós nos aproximamos e interpretamos a realidade. Com tais observações, o sujeito branco é assegurado de seu lugar de poder e autoridade sobre um grupo que ele está classificando como "menos inteligente". (KILOMBA, 2019, p. 55).
}

Esta escritora portuguesa llama la atención respecto del "lugar de enunciación” de quien toma la palabra en nombre de un saber. Y marca insistentemente, en la línea de bell hooks, que el pensamiento negro nunca estuvo ni está desligado de la práctica, no como un ejercicio romántico, de celebración de una identidad, sino como un espacio de resistencia, reconfigurando las coordenadas de representación.

Hablar desde una primera persona e incluir a los cuerpos en nuestros discursos se torna, así, una cuestión urgente no solamente en las subjetividades negras sino también, y sobre todo, blancas, para poder desenmascarar a la supuesta objetividad de ciertas voces y dejar en evidencia la brecha que existe entre quienes están autorizados a ser escuchados y quienes se desplazan hacia nichos marginalizados dentro de la academia. Como propone Kilomba: "Demando uma epistemologia que inclua o pessoal e o subjetivo como parte do discurso acadêmico, pois todas/os nós falamos de um tempo e lugar 
específicos, de uma história e uma realidade específicas - não há discursos neutros" (KILOMBA, 2019, p. 58). Se trata, en definitiva, de poner en funcionamiento un ejercicio de descolonizar el pensamiento.

Resulta fundamental recordar insistentemente, entre quienes trabajamos con el lenguaje, que nuestro lugar de habla dice mucho de lo que decimos y que resulta urgente sincerarnos.

\section{CONCLUSIÓN}

Este artículo se centró en el análisis de diversos trabajos de críticas literarias argentinas y brasileñas inclinadas todas hacia la concepción de una idea de literatura que supera los límites que impone el campo literario, expandiéndose hacia otros lenguajes y reglas. Lo que me interesó profundizar no es esa hipótesis tan desarrollada por muchos otros críticos y críticas literarias ligada a la postautonomía y abordada desde diversas categorías, como "frutos extraños" (GARRAMUÑO, 2014) o "literatura expandida" (PATO, 2013). El foco de atención aquí se centró en el análisis de ciertas producciones críticas que desplazaron los cuestionamientos respecto de los límites en relación con la idea de literatura al campo de la crítica a partir de la realización de trabajos experimentales que no responden a las pautas académicas de producción de conocimiento. Se trata de composiciones que dialogan con la hora histórica y con las historias de vida de cada una de las autoras y, desde ahí, proyectan las discusiones teóricas y críticas respecto de la literatura.

El estudio comparativo de este conjunto de producciones evidencia que este modo de hacer crítica coincide con momentos de crisis política radical en los países de origen de cada autora. Por otro lado, la puesta en común de todas estas propuestas puede ser entendida a la luz del concepto de performance, en tanto y en cuanto ese concepto aúna las operaciones ligadas al lugar de habla, al soporte, al momento de producción y a la intervención disciplinar que todas ellas llevan a cabo. Finalmente, el análisis de este conjunto de producciones apunta al autocuestionamiento del lugar de privilegio de ciertas voces, en función de sostener una idea de literatura y una idea de crítica que sea más plural, diversa y antirracista.

\section{REFERÊNCIAS}

AGUILAR, Gonzalo; CÁMARA, Mario. La máquina performática: la literatura en el campo experimental. Buenos Aires: Grumo, 2019.

ARFUCH, Leonor. El espacio biográfico: dilemas de la subjetividad contemporánea. Buenos Aires: Fondo de Cultura Económica, 2010.

AYERBE, Nerea. Documentando lo efímero: reconsideración de la idea de presencia en los debates sobre la performance. Revista Brasileira de Estudos da Presença, Porto Alegre, v. 7, n. 3, set./dez. 2017, p. 551-572.

BARTHES, Ronald. ¿Qué es la crítica?. In: BARTHES, Ronald. Ensayos críticos. Buenos Aires: Seix Barral, 2003. p. 345-352.

BARTHES, Ronald. La preparación de la novela. Tradução Patrícia Wilson. México: Siglo XXI, 2005. 
BARTHES, Ronald. Lección inaugural de la Cátedra de Semiología del Collège de France, pronunciada el 7 de enero de 1977. In: BARTHES, Ronald. El placer del texto y lección inaugural. Madrid: Siglo XXI, 1998. p. 111-150.

BARTHES, Ronald. Mucho tiempo he estado acostándome temprano. In: BARTHES, Ronald. El susurro del lenguaje. Barcelona: Seix Barral, 2009. p. 391-407.

BOGADO, Maria. Rua. In: HOLLANDA, Heloísa Buarque (org.). Explosão feminista: arte, cultura, política e universidade. São Paulo: Companhia das Letras, 2018. p. 23-72.

BOURDIEU, Pierre. Las reglas del arte: génesis y estructura del campo literario. Barcelona: Anagrama, 1995.

DELEUZE, Gilles. En medio de Spinoza. Buenos Aires: Cactus, 2003.

GARCIA, Marília. Parque das ruínas. Rio de Janeiro: Luna Parque, 2018.

GARRAMUÑO, Florencia. Frutos estranhos: sobre a inespecificidade na estética contemporânea. Rio de Janeiro: Rocco, 2014.

HOLLANDA, Heloísa Buarque (org.). Explosão feminista: arte, cultura, política e universidade. São Paulo: Companhia das Letras, 2018.

KILOMBA, Grada. Memórias da plantação: episodios de racismo cotidiano. Tradução Jess Oliveira. Rio de Janeiro: Cobogó, 2019.

KLINGER, Diana. Entrevista oferecida para o curso de pós-graduação "El lugar de la crítica y del crítico frente a las literaturas contemporáneas”. Facultad de Filosofía y Letras, Universidad de Buenos Aires, 18 de fevereiro de 2020.

KLINGER, Diana. Escritas de si, escritas do outro: o retorno do autor e a virada etnográfica. Rio de Janeiro: 7Letras, 2007.

KLINGER, Diana. Literatura e ética: da forma para a força. Rio de Janeiro: Rocco, 2014.

LUDMER, Josefina. Aquí América Latina: una especulación. Buenos Aires: Eterna Cadencia, 2010.

MIGUEL, Luis Felipe. O colapso da democracia no Brasil: da constituição ao golpe de 2016. São Paulo: Fundação Rosa de Luxemburgo, Expressão Popular, 2019.

PATO, Ana. Literatura expandida - arquivo e citação na obra de Dominique Gonzalez-Foerster. São Paulo: Edições Sesc, 2013.

RICHARD, Nelly. Campos cruzados: arte, cultura y diálogos infocomunicacionales. La Habana: Cuadernos Casa de las Américas, 2009.

SONTAG, Susan. Contra la interpretación. Tradução Horacio Vázquez Rial. Barcelona: Seix Barral, 1984.

STIGGER, Verónica. Delírio de damasco. Florianópolis: Cultura e Barbárie, 2013.

SÜSSEKIND, Flora. “Limites incertos”. Palestra realizada no Programa de Pós-graduação em Arquitetura e o Curso de Arquitetura e Urbanismo da PUC-Rio. 14 de abril de 2014. 
SÜSSEKIND, Flora. A crítica como papel de bala. O Globo. [S. 1.], 24 abr. 2010. Disponível em: https://blogs. oglobo.globo.com/prosa/post/a-critica-como-papel-de-bala-286122.html. Acesso em: 1 set. 2021.

SÜSSEKIND, Flora. Objetos verbais não identificados: um ensaio de Flora Süssekind. O Globo. [S. 1.], 21 set. 2013. Disponível em: https://blogs.oglobo.globo.com/prosa/post/objetos-verbais-nao-identificados-umensaio-de-flora-sussekind-510390.html. Acesso em: 1 set. 2021.

TAYLOR, Diana. Performance. Buenos Aires: Asunto Impreso, 2012.

VIDAL, Paloma. Em obras: saídas da fição. Malha Fina Cartonera. [S. 1.], 10 nov. 2016. Disponível em: https:// malhafinacartonera.wordpress.com/2016/11/10/em-obras-saidas-da-ficcao/. Acesso em: 1 set. 2021. 